\title{
PENGUKURAN KONSTANTA HENRY TOLUEN DAN BENZEN DALAM MINYAK DAN AIR DENGAN KOLOM GELEMBUNG
}

\author{
Suhartono, Herri Susanto*, Dwiwahju Sasongko, dan Azis Trianto \\ Kelompok Keahlian Energi dan Sistem Pemroses Teknik Kimia \\ Fakultas Teknologi Industri, Institut Teknologi Bandung \\ Jalan Ganesha 10 Bandung 40132 \\ Email: herri@che.itb.ac.id
}

\begin{abstract}
Abstrak
Pengukuran konstanta Henry sistem toluen dan benzen dalam minyak dan air dilakukan melalui percobaan absorpsi di dalam sebuah kolom gelembung dengan diameter $3 \mathrm{~cm}$. Minyak sawit, minyak bunga matahari, minyak pelumas dan air digunakan sebagai absorben. Toluen dan benzen dipilih sebagai tar model. Gas model yang tersusun dari udara dan uap toluen atau benzen digelembungkan ke dalam absorben $50 \mathrm{~mL}$. Absorpsi dilakukan pada suhu 30 dan $60{ }^{\circ} \mathrm{C}$ dan laju alir gas model 13,6 mL/min. Analisa dilakukan terhadap konsentrasi aliran gas model sebelum dan sesudah absorpsi. Analisa tersebut dilakukan dengan kromatografi gas Shimadzu GC-8APF. Konstanta Henry dihitung sebagai $\mathrm{H}=\mathrm{C}_{\mathrm{G}} / \mathrm{C}_{\mathrm{L}}$ dan $\mathrm{H}=\mathrm{P} / \mathrm{C}_{\mathrm{L}}$. Nilai $1 / \mathrm{H}$ sistem toluen-minyak pelumas dan toluen-minyak sawit pada suhu $30{ }^{\circ} \mathrm{C}$ dan laju alir gas 13,6 mL/min berturut-turut adalah 155 dan 145 (untuk $\mathrm{C}_{\mathrm{G}}$ dalam mol/L dan $\mathrm{C}_{\mathrm{L}}$ dalam mol/L). Merujuk pada nilai-nilai konstanta Henry hasil percobaan, minyak pelumas dan minyak sawit merupakan cairan penyerap yang paling cocok untuk toluen dan benzen sebagai representasi tar dalam gas hasil gasifikasi. Urutan besarnya kapasitas absorpsi cairan penyerap terhadap toluen dan benzen adalah sebagai berikut (berturut-turut dari yang besar): minyak pelumas, minyak sawit, minyak bunga matahari dan air. Konstanta Henry toluen dalam air berada pada kisaran 4, yang menunjukkan bahwa kapasitas absorpsi toluen dalam air lebih rendah dibandingkan kapasitas absorpsi toluen dalam minyak.
\end{abstract}

Kata Kunci : absorpsi, konstanta Henry, toluen, benzen, gas produser

\begin{abstract}
Determination of Henry's constant for toluene and benzene in oils and water were carried out in a bubbling bottle with diameter of $3 \mathrm{~cm}$. Air containing toluene vapour or benzene vapour was bubbled through $50 \mathrm{~mL}$ absorbing liquid. The gas flow rate was $13.6 \mathrm{~mL} / \mathrm{min}$. By measuring the concentration of toluene or benzene in the inlet and outlet gas stream, we were able to calculate their concentrations in absorbing liquid. We found that the value of Henry's constant of toluene in lubrication oil and palm oil at $30{ }^{\circ} \mathrm{C}$ were 155 and 145 respectively $\left(\mathrm{H}=\mathrm{C}_{\mathrm{G}} / \mathrm{C}_{\mathrm{L}}\right.$, with $\mathrm{C}_{\mathrm{G}}$ in mol/L and $\mathrm{C}_{\mathrm{L}}$ in mol/L). We also found that the absorption capacities were in the order (from the highest) of: lubrication oil, palm oil, and sunflower oil. Henry's constant of toluene in water was at about 4 which was much lower than those of oils.
\end{abstract}

Keyword : absorption, Henry's constant, toluene, benzene, producer gas

*korespondensi 


\section{Pendahuluan}

Permasalahan yang sering dihadapi dalam aplikasi teknologi gasifikasi biomassa adalah kandungan tar yang terdapat dalam gas produser. Tar yang mengembun akan menyebabkan penyumbatan di dalam saluran perpipaan dan peralatan pada sistem pendingin dan pembersih gas produser. Salah satu teknik penyisihan tar dari gas produser di luar gasifier adalah dengan proses absorpsi.

Penelitian ini merupakan bagian dari pengembangan sistem pembersih gas hasil gasifikasi, berupa penyisihan tar dengan metoda absorpsi menggunakan berbagai absorben. Variabel kunci dari metoda ini berupa pemilihan absorben yang cocok untuk menyerap senyawa-senyawa tar. Pemilihan absorben tersebut harus memenuhi beberapa kriteria; (i) mempunyai kapasitas absorpsi yang besar, (ii) viskositas rendah dan koefisien difusi yang tinggi, (iii) tekanan uap rendah dan (iv) murah (Heymes, dkk., 2006). Absorben organik diperkirakan cocok digunakan sebagai absorben untuk penyerap tar, karena senyawa-senyawa utama di dalam tar pada umumnya merupakan senyawasenyawa organik yang mudah menguap (VOC, volatile organic compound).

Penelitian ini bertujuan untuk membandingkan kemampuan beberapa absorben untuk menyerap toluen dan benzen sebagai model tar, melalui penentuan nilai konstantra Henry. Hasil-hasil penentuan nilai konstanta Henry, H dari data eksperimental digunakan sebagai kriteria pemilihan absorben.

\section{Teori Dasar}

Absorpsi merupakan satuan proses pemisahan dengan cara mengontakkan dua fasa yang berbeda. Dalam fasa gas dan cairan, solut A diabsorpsi dari fasa gas ke dalam fasa cair. Proses tersebut melibatkan peristiwa difusi molekuler atau perpindahan massa solut A melalui gas diam yang tak berdifusi ke dalam suatu cairan, hingga mencapai kejenuhan di kedua fasa tersebut. Agar dapat memprediksi konsentrasi solut dalam masingmasing fasa diperlukan data-data eksperimental sampai mencapai kejenuhan. Faktor-faktor yang mempengaruhi kejenuhan solut dalam absorben adalah suhu, tekanan parsial dan konsentrasi.

Pada tekanan rendah dan kelarutan gas ke dalam fasa cairan kecil, hukum Henry digunakan untuk mendapatkan hubungan antara konsentrasi kesetimbangan solut di fasa gas terhadap yang di fasa cair. Dengan mengasumsikan fasa gas sebagai gas ideal, nilai konstanta Henry tak berdimensi dapat dinyatakan dengan persamaan 1 ((Vuong dkk., 2009) dkk., 2009).

$$
\mathrm{H}=\frac{\mathrm{C}_{\mathrm{G}}}{\mathrm{C}_{\mathrm{L}}}
$$

Hukum Henry juga dapat dinyatakan sebagai kelarutan dalam besaran fraksi berat solut gas di dalam absorben pada tekanan parsial tertentu. Hubungan konstanta Henry fraksi berat (weight-fraction Henry's constant) dan konsentrasi solut dapat dinyatakan dalam persamaan 2 (Iwai dkk., 1981).

$$
\mathrm{H}^{*}=\frac{\mathrm{P} \cdot \mathrm{y}_{\mathrm{A}}}{\mathrm{w}_{\mathrm{A}}}
$$

dengan $\mathrm{P}$ tekanan total sistem, $\mathrm{y}_{\mathrm{A}}$ fraksi solut A di fasa gas dan $\mathrm{w}_{\mathrm{A}}$ fraksi berat solut A dalam absorben.

Di dalam percobaan kolom gelembung, konsentrasi solut di dalam absorben dihitung secara eksperimental dari selisih konsentrasi solut di fasa gas pada aliran gas masuk dan keluar absorber setiap waktu. Menggunakan hasil integrasi $\mathrm{C}_{\mathrm{G}, \mathrm{o}}$ terhadap waktu dan neraca massa antara aliran masuk dan keluar kolom gelembung, konsentrasi gas terlarut di dalam absorben dapat dihitung dengan menggunakan persamaan 3 (Vuong dkk., 2009).

$\mathrm{C}_{\mathrm{L}} \mathrm{V}_{\mathrm{L}}=\mathrm{Q}_{\mathrm{G}} \int_{0}^{\mathrm{t}}\left(\mathrm{C}_{\mathrm{G}, \mathrm{i}}-\mathrm{C}_{\mathrm{G}, \mathrm{o}}\right) \mathrm{dt}$

dengan $\mathrm{C}_{\mathrm{G}, \mathrm{i}}$ dan $\mathrm{C}_{\mathrm{G}, \mathrm{o}}$ adalah konsentrasi solut $\mathrm{di}$ fasa gas saat masuk dan yang saat keluar kolom gelembung. $\mathrm{Q}_{\mathrm{G}}$ adalah laju alir gas dan $\mathrm{V}_{\mathrm{L}}$ volume absorben.

\section{Metodologi}

Percobaan absorpsi toluen dan benzen dilakukan dalam skala laboratorium, peralatan percobaan secara skematik diperlihatkan Gambar 1. Gas model dibuat dengan menggelembungkan udara ke dalam cairan toluen atau benzen. Variasi konsentrasi toluen atau benzen dalam udara dibuat dengan cara mengalirkan udara pada berbagai laju alir ke dalam cairan toluen atau benzen murni di dalam sebuah kolom gelas gelembung.

Kolom pembuat gas model dan absorber berukuran $200 \mathrm{~mL}$ dan diameter 3 $\mathrm{cm}$. Kolom absorber dilengkapi dengan pipa pendistribusi dan penggelembung gas berdiameter $6 \mathrm{~mm}$. Laju alir gas model yang 
masuk ke dalam kolom gelembung dilakukan dengan mengatur laju alir udara menggunakan precision stainless steel needle valve dan diukur menggunakan rotameter.

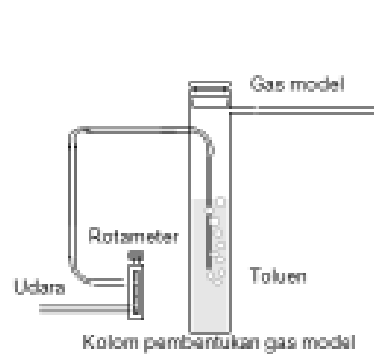

Gambar 1. Skema percobaan

Campuran gas dengan konsentrasi gas model tertentu digelembungkan ke dalam kolom absorber berisi berbagai minyak dan air sebagai absorben. Lima puluh $\mathrm{mL}$ absorben digunakan di dalam kolom gelembung tanpa penambahan absorben segar. Minyak sawit (pure palm oil), minyak bunga matahari (sunflower oil), minyak pelumas (lubrication oil) dan air digunakan sebagai absorben. Semua percobaan absorpsi toluen atau benzen dilakukan pada suhu absorben 30 atau $60{ }^{\circ} \mathrm{C}$, dan laju alir gas model 13,6 $\mathrm{mL} / \mathrm{min}$.

Konsentrasi toluen atau benzen dalam aliran gas dianalisa setiap 30 menit menggunakan kromatografi gas dengan flame ionization detector (GC/FID), Shimadzu GC8APF dilengkapi perekam chromopac C-CR6A. Suhu injektor $250{ }^{\circ} \mathrm{C}$, kolom $100{ }^{\circ} \mathrm{C}$ dan detektor $250^{\circ} \mathrm{C}$.

Konsentrasi toluen atau benzen diukur pada aliran gas masuk dan keluar kolom gelembung dan dinyatakan sebagai $\mathrm{C}_{\mathrm{G}, \mathrm{i}}$ dan $\mathrm{C}_{\mathrm{G}, \mathrm{o}}$, sedangkan konsentrasi solut di fasa cair dihitung dengan menggunakan Persamaan (3) di atas, sebagai $C_{L}$.

\section{Hasil dan Pembahasan}

Sebuah contoh data percobaan pengukuran konsentrasi toluen dalam udara saat masuk dan keluar kolom gelembung dan dalam absorben disajikan pada Gambar 2 . Kondisi kesetimbangan diasumsikan, ketika konsentrasi solut di fasa gas masuk kolom gelembung mendekati konsentrasi solut di fasa gas saat keluar keluar kolom gelembung, $\mathrm{C}_{\mathrm{G}, \mathrm{i}} \approx \mathrm{C}_{\mathrm{G}, \mathrm{o}}$. Pada saat tersebut, konsentrasi solut di fasa cair merupakan konsentrasi solut jenuh dalam absorben. Konsentrasi jenuh dicapai setelah kira-kira 600 menit untuk setiap pasangan toluen-minyak dan benzen-minyak. Pasangan toluen-air dan benzen-air konsentrasi kejenuhan dicapai pada waktu kira-kira 150 menit. Contoh konsentrasi kejenuhan disajikan pada Tabel 1 dan Tabel 2.

Nilai-nilai konstanta Henry untuk masing-masing pasangan solut-absorben dihitung menggunakan Persamaan (1) atau Persamaan (2). Contoh nilai-nilai konstanta Henry hasil percobaan dan dari literatur disajikan pada Tabel 3. Nilai H ini merupakan besaran yang penting pada proses absorpsi gas, karena nilai $\mathrm{H}$ secara termodinamik memberikan arti bahwa komposisi toluen dan benzen fasa gas dan cair berada pada saat kejenuhan. Semakin besar nilai $1 / \mathrm{H}$ atau semakin kecil nilai $\mathrm{H}$ untuk suatu pasangan solut-absorben menunjukkan bahwa solut tersebut makin mudah terlarut di dalam absorben.

Minyak pelumas mempunyai kapasitas absorspsi paling tinggi dibanding absorben lainnya, ditunjukkan oleh nilai konstanta Henry, $\mathrm{H}$ terkecil untuk pasangan toluenminyak pelumas dan benzen-minyak pelumas. Minyak sawit mempunyai kapasitas absorpsi lebih mirip dengan minyak pelumas. Air mempunyai kapasitas absorpsi paling rendah, ditunjukkan oleh nilai-nilai konstanta Henry yang besar terhadap pasangan toluen-air dan benzen-air [(Vuong dkk., 2009), M.D., dkk, 2009].

Perbedaan kapasitas penyerapan tergantung pada sifat fisika dan kimia dari solut dan absorben yang digunakan sebagai media penyerap. Sifat-sifat fisika yang dapat mempengaruhi penyerapan dari solut adalah densitas, viskositas cairan, kelarutan (solubility) ukuran molekul dan struktur molekul dan difusivitas solut dalam absorben.

Sifat-sifat kimiawi, seperti kepolaran solut dan absorben dan bentuk senyawa hidrokarbon alifatik (linier dan non linier) atau aromatik dan sifat alamiah hidrofobik dan hidrofilik solut dapat pula berpengaruh terhadap jumlah solut yag dapat terserap oleh absorben. Minyak nabati merupakan ester gliserida atau asam lemak (gliserida), sedangkan unsur dasar minyak pelumas merupakan rantai panjang alkana. Gliserida tersusun dari beberapa atom oksigen di dalam struktur molekulnya. Atom oksigen di dalam minyak nabati dapat menurunkan sifat kepolaran minyak tersebut, karena itu menyebabkan lebih rendahnya kapasitas penyerapan terhadap toluen dan benzen yang 


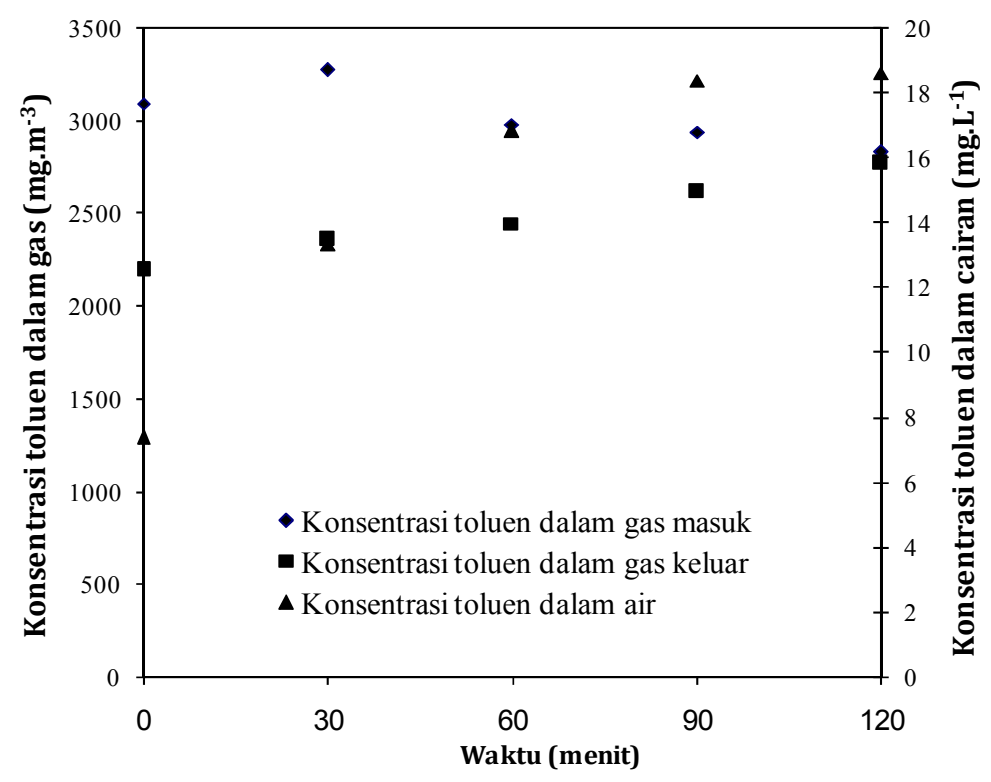

(a)

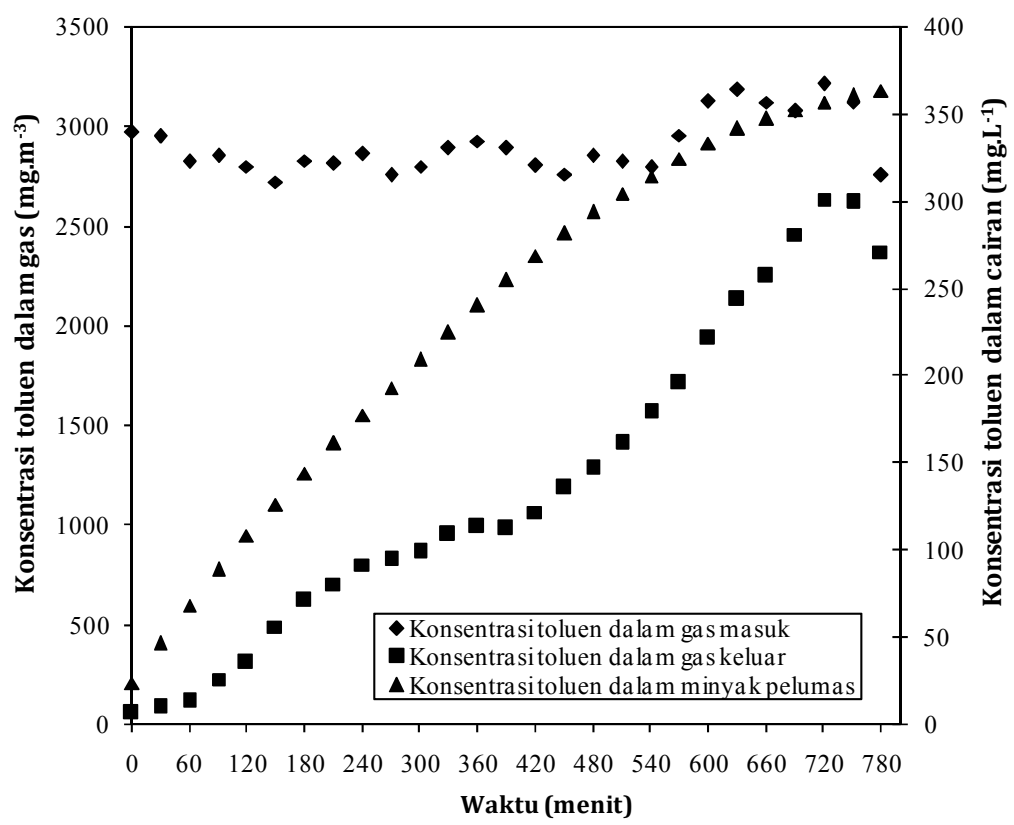

(b)

Gambar 2. Konsentrasi toluen di dalam fasa gas dan cairan penyerap pada $Q \mathrm{~g}=13,6 \mathrm{ml} / \mathrm{min}$ dan $\mathrm{T}=30^{\circ} \mathrm{C}$. (a) sistem toluen-air; (b) sistem toluen-minyak pelumas.

bersifat nonpolar. Toluen dan benzen bersifat nonpolar juga hidrofobik, sedikit larut dalam air yang bersifat polar. Gugus metil senyawa toluen dapat meningkatkan sifat kepolaranya dan ukuran molekul dari solut tersebut, yang akan menurunkan kelarutan dan difusivitas dalam air dibandingkan benzen (Ozturk danYilmaz, 2006).
Dari semua kajian data percobaan yang didapat memperlihatkan bahwa urutan besarnya kapasitas absorpsi absorben terhadap toluen dan benzen sebagai berikut (berturut-turut dari tinggi ke rendah): minyak pelumas, minyak sawit, minyak bunga matahari dan air. 
Tabel 1. Konsentrasi toluen dan benzen saat jenuh pada $Q_{G}=13,6 \mathrm{~mL} / \mathrm{min}$ dan $T=30^{\circ} \mathrm{C}$

\begin{tabular}{lcccccc}
\hline & \multicolumn{3}{c}{ Toluen } & \multicolumn{3}{c}{ Benzen } \\
\cline { 2 - 7 } & $\begin{array}{c}\mathrm{C}_{\mathrm{G}, \mathrm{i}} \\
\left(\mathrm{mg} / \mathrm{m}^{3}\right)\end{array}$ & $\begin{array}{c}\mathrm{C}_{\mathrm{G}, \mathrm{o}} \\
\left(\mathrm{mg} / \mathrm{m}^{3}\right)\end{array}$ & $\begin{array}{c}\mathrm{C}_{\mathrm{L}} \\
(\mathrm{mg} / \mathrm{L})\end{array}$ & $\begin{array}{c}\mathrm{C}_{\mathrm{G}, \mathrm{i}} \\
\left(\mathrm{mg} / \mathrm{m}^{3}\right)\end{array}$ & $\begin{array}{c}\mathrm{C}_{\mathrm{G}, \mathrm{o}} \\
\left(\mathrm{mg} / \mathrm{m}^{3}\right)\end{array}$ & $\begin{array}{c}\mathrm{C}_{\mathrm{L}} \\
(\mathrm{mg} / \mathrm{L})\end{array}$ \\
\hline Minyak sawit & 2815 & 2449 & 341 & 42520 & 37417 & 3120 \\
Minyak bunga matahari & 2976 & 2380 & 289 & 44351 & 42134 & 2821 \\
Minyak pelumas & 3123 & 2249 & 348 & 43975 & 31662 & 3590 \\
Air & 2830 & 2773 & 19 & 42518 & 40817 & 425 \\
\hline
\end{tabular}

Tabel 2. Konsentrasi toluen dan benzen saat jenuh pada $Q_{G}=13,6 \mathrm{~mL} / \mathrm{min}$ dan $T=60{ }^{\circ} \mathrm{C}$

\begin{tabular}{lcccccc}
\hline & \multicolumn{3}{c}{ Toluen } & \multicolumn{3}{c}{ Benzen } \\
\cline { 2 - 7 } & $\begin{array}{c}\mathrm{C}_{\mathrm{G}, \mathrm{i}} \\
\left(\mathrm{mg} / \mathrm{m}^{3}\right)\end{array}$ & $\begin{array}{c}\mathrm{C}_{\mathrm{G}, \mathrm{o}} \\
\left(\mathrm{mg} / \mathrm{m}^{3}\right)\end{array}$ & $\begin{array}{c}\mathrm{C}_{\mathrm{L}} \\
(\mathrm{mg} / \mathrm{L})\end{array}$ & $\begin{array}{c}\mathrm{C}_{\mathrm{G}, \mathrm{i}} \\
\left(\mathrm{mg} / \mathrm{m}^{3}\right)\end{array}$ & $\begin{array}{c}\mathrm{C}_{\mathrm{G}, \mathrm{o}} \\
\left(\mathrm{mg} / \mathrm{m}^{3}\right)\end{array}$ & $\begin{array}{c}\mathrm{C}_{\mathrm{L}} \\
(\mathrm{mg} / \mathrm{L})\end{array}$ \\
\hline Minyak sawit & 2956 & 2737 & 308 & 44316 & 40770 & 3047 \\
Minyak bunga matahari & 3307 & 2751 & 266 & 44352 & 42106 & 2705 \\
Minyak pelumas & 2791 & 2112 & 333 & 43996 & 39156 & 3307 \\
Air & 2905 & 2773 & 16 & 45740 & 42995 & 422 \\
\hline
\end{tabular}

Tabel 3. Konstanta Henry untuk toluen dan benzen dari data percobaan dan literatur

\begin{tabular}{llcccccc}
\hline & & \multicolumn{3}{c}{$1 / \mathrm{H}\left(\mathrm{H}=\mathrm{C}_{\mathrm{G}} / \mathrm{C}_{\mathrm{L}}\right)$} & \multicolumn{3}{c}{$\mathrm{H}^{*}=\mathrm{y}_{\mathrm{A} . \mathrm{P} / \mathrm{w}_{\mathrm{A}}}$} \\
\cline { 2 - 7 } & Sistem & \multicolumn{2}{c}{ Percobaan } & Literatur & \multicolumn{2}{c}{ Percobaan } & Literatur \\
& Miyak sawit & $145 \mathrm{~K}$ & $333 \mathrm{~K}$ & $298 \mathrm{~K}$ & $303 \mathrm{~K}$ & $333 \mathrm{~K}$ & $298 \mathrm{~K}$ \\
\hline Minyak bunga & 121 & 135 & - & 1,7 & 1,8 & - \\
& matahari & & 97 & - & 1,9 & & - \\
\multirow{5}{*}{ Toluen } & Minyak pelumas & 155 & 158 & - & 1,6 & 1,6 & - \\
& Air & 7 & 6 & $4[4]$ & 39,5 & 42,8 & $60.90[4]$ \\
& di(2-ethylhexyl) & - & - & $2821[1,4]$ & - & - & $0,04[4]$ \\
& adipate (DEHA) & & & & & & \\
& n-Hexadecane & - & - & $990[4]$ & - & - & $0.20[4]$ \\
\hline \multirow{5}{*}{ Benzen } & Miyak sawit & 83 & 75 & - & 3,4 & 3,8 & - \\
& Minyak bunga & 67 & 64 & - & 4,1 & 4,2 & - \\
& matahari & & & & & & \\
& Minyak pelumas & 94 & 78 & - & 3,1 & 3,7 & - \\
& Air & 10 & 10 & - & 30,1 & 31,1 & - \\
\hline
\end{tabular}

[1] Heymes dkk., 2006 [4] Vuong dkk., 2009

\section{Kesimpulan}

Nilai konstanta Henry pasangan toluenminyak pelumas dan toluen-minyak sawit pada suhu $30^{\circ} \mathrm{C}$ dan laju alir gas $13,6 \mathrm{~mL} / \mathrm{min}$ berturut-turut 155 dan $145\left(\mathrm{H}=\mathrm{C}_{\mathrm{G}} / \mathrm{C}_{\mathrm{L}}\right)$. Merujuk pada nilai $\mathrm{H}$ hasil percobaan, minyak pelumas dan minyak sawit merupakan absorben yang paling cocok untuk benzen dan toluen sebagai representasi tar dalam gas produser. Minyak pelumas dan minyak sawit mempunyai kapasitas absorpsi lebih baik dan waktu kejenuhan lebih lama dibandingkan air. Minyak dapat menggantikan air sebagai absorben untuk digunakan dalam sistem pembersihan gas hasil gasifikasi.

\section{Ucapan Terima Kasih}

Penulis menyampaikan terimakasih kepada Departemen Pendidikan Nasional Republik Indonesia atas Beasiswa BPPS dan Program Sandwich like.

Penelitian ini terkait dengan program Pengembangan Teknologi Gasifikasi Biomassa Yang Ramah Lingkungan dengan biaya dari Yayasan Bhakti Tanoto. Percobaan dilakukan di Tokyo University of Agriculture and Technology (TUAT), Jepang. 


\section{Daftar Simbol}

$\mathrm{C}_{\mathrm{G}, \mathrm{i}}, \mathrm{C}_{\mathrm{G}, \mathrm{o}}$ konsentrasi gas masuk dan keluar (mol/L atau $\mathrm{mg} / \mathrm{m}^{3}$ )

$\mathrm{C}_{\mathrm{L}} \quad$ konsentrasi senyawa terlarut dalam cairan penyerap (mol/L atau $\mathrm{mg} / \mathrm{L}$ )

$\mathrm{C}_{\mathrm{L}}{ }^{\mathrm{E}} \quad$ konsentrasi senyawa terlarut dalam cairan penyerap saat jenuh (mg / L)

$\mathrm{C}_{\mathrm{G}} \quad$ konsentrasi senyawa terlarut dalam fasa gas (mol/L atau mg /L)

$\mathrm{H} \quad$ konstanta Henry tak berdimensi, Persamaan (1)

$\mathrm{H}^{*} \quad$ konstanta Henry (atm/fraksi berat), Persamaan (2)

1/H kelarutan

$\mathrm{P} \quad$ tekanan total (atm)

$\mathrm{Q}_{\mathrm{G}} \quad$ laju alir gas $(\mathrm{mL} / \mathrm{min})$

$\mathrm{V}_{\mathrm{L}} \quad$ cairan penyerapt volume $\left(\mathrm{m}^{3}\right)$

$\mathrm{w}_{\mathrm{A}} \quad$ fraksi mol senyawa terlarut A dalam absorben

$\mathrm{y}_{\mathrm{A}} \quad$ fraksi mol senyawa terlarut A dalam absorben

t $\quad$ waktu (menit)

\section{Daftar Pustaka}

Heymes, F.; Manno-Demoustier, P.; Charbit, F.; Fanlo, J. L.; Moulin, P., A new efficient absorption liquid to treat exhaust air loaded with toluene, Chemical Engineering Journal, 2006, Vol. 115(3), 225-231.

Iwai, Y.; Anai, Y.; Arai, Y., Prediction of Solubilities for Volatile Hydrocarbons in LowDensity Polyethylene Using UNIFAC-FV Model, Polymer Engineering and Science, 1981, Vol. 21(15), 1015-1018.

Ozturk, B.; Yilmaz, D., Absorptive Removal of Volatile Organic Compound From Flues Gas Streams, Trans IChemE, Part B, Process Safety and Environmental Protection, 2006, Vol. 84(B5), 391-398.

Vuong, M. D.; Couvert, A.; Couriol, C.; Amrane, A.; Le Cloirec, P., Determination of the Henry's Constant and the Mass Transfer Rate of VOCs in Solvent, Chemical Engineering Journal, 2009, Vol. 150(2-3), 426-430. 